\title{
CORRESPONDENCE
}

\author{
TO THE EDITOR OF Philosophy
}

\section{THE PHYSICAL WORLD AND REALITY}

SiR,

As a layman I must, in common with the majority of people, formulate a theory of the physical world and reality from whatever unspecialized knowledge I possess; being guided to some extent only by those better qualified to express an opinion than myself. Nevertheless, on reading Mr. Gomborow's article in the October issue of Philosophy, I feel constrained to enter a caveat against his complaisant suggestion that, because such tautological explanations as that the sun attracts the earth because it does, or that zinc displaces copper in solutions because it does, fail to satisfy an intelligent person, the real explanation must necessarily be the simple fact that God has willed they should.

With respect I would suggest that the latter theory not only is less acceptable to many intelligent persons than the former, but also does unpardonable violence to the idea of Immanent Deity. If we accept Mr. Gomborow's theory, as a logical consequence, we perforce accept the following a priori hypotheses, namely, (a) All "laws" of nature are "laws" extrinsic to reality; "laws," that is to say, imposed by Transcendent Will on an otherwise chaotic universe; and $(b)$ the universe is essentially static, and its present-day dynamic quality is, or was, occasioned by some agency "outside" of and independent of reality. In other words, we are back at the mental stage of our nurseries when the image of God, first making the clock and then winding it up, was used to stultify our first questionings. Surely the physical world (or any other world for that matter) is the world made manifest to us through, and only through, one or more of the very limited number of senses with which we have been endowed. This world we know as a world essentially dynamic, and, if you like the expression, as a world essentially "orderly" - that is, a world exhibiting certain well-perceived and well-defined "laws"; but surely, again, that fact offers no reason at all for envisaging the world as amenable to those "laws," or for imputing those "laws" to anything other than intrinsic aspects of reality.

We appreciate those "laws" in much the same way as we appreciate the "greenness" of the visual world. They are "good" for us simply because they are, and not because it is good for us that they should be: The great drawback with most scientists and philosophers is that they are unable to recognize in this dynamic quality, in this orderliness, essential characteristics of the physical world; but only imposed and, as it were, incidental, characteristics. I feel that if Mr. Gomborow could see his way to attempt another hypothesis of the universe based this time on the assumption that things are simply because they are, the result would be instructive; provided only (and the proviso is important!) he embraced in that hypothesis a conception of Immanent Deity willing the best in man and infinite in potentiality for man's becoming.

I am, Sir, yours faithfully,

LoNg SUTTON, LincolnshiRe, Frank W. ROBINSON. October 3o, 1935.

To THE Editor of Philosophy

\section{PHILOSOPHY AND PRACTICAL ETHICS}

My Dear Editor,

Two passages in your October issue have so impressed my mind that I feel moved to write you about them. One of them occurs on page $48 \mathrm{r}$, in Mr. J. L. Stock's 